\title{
Orthopedic Pathology in Croatia - 20 years single center experience.
}

The University of Zagreb was founded in 1669 by Jesuits during the reign of king Leopold of Austria. It was only in 1917 the Medical School was founded with the Institute and University Department of Pathology becoming functional as of 1922 . The first Head of the Institute was Professor Sergei Saltykow. Russian by birth, he was educated and working in many famous institutions of that time, including the laboratories of Mechnikow, Pasteur, Ribbert and Kaufmann. In 1965, the clinical disciplines were organizationally separated in the Clinical Hospital Center Rebro (KBC Rebro) later KBC Zagreb. The Pathology Department was split in two with one remaining the Institute of Pathology of the Medical School giving pathology service mainly to outside hospitals and the other becoming the Clinical Department of Pathology giving pathology service to the clinical units of KBC Rebro. Staff members are serving both departments.

The accessed period includes years 1999 till 2018. During this period several pathologist were members of the team, which was established years before by Professor Bogdan Krstulovic, followed by Dr Mira Devcic. Staff members were in historical order Spomenka Manojlovic, Sven Seiwerth, Simun Krizanac, Zdenka Hutinec, Luka Brcic and Lovorka Batelja. In its diagnostic work the team in a closest way cooperates with the Department of Diagnostic and Interventional Radiology KBC Zagreb, mostly with Professor Kristina Potocki. During the accessed period the team was diagnostically covering several in-house and extramural surgically active departments in Zagreb (Department of Orthopaedic Sur- gery, KBC Zagreb, Departments of Oncology and Surgery Childrens Clinic Klaiceva, Departments of Surgery, Traumatology and Neurosurgery KBC Zagreb, Trauma clinic Zagreb) as well as external hospitals consultations (representing arr. $2.55 \%$ of material).

The review includes 6449 patients with orthopedic diagnoses established in the center. Of these, $54 \%$ were diagnosed with tumors and $46 \%$ with non-tumorous disease. Synovial changes were the most common diagnosed pathology, and among tumors and tumor-like lesions osteochondromas followed by osteosarcoma and ganglion cyst followed by chondrosarcoma. The list including rare lesions (appearing with less than $2 \%$ in our material) is expectedly long.

In 2003 molecular diagnostics of bone tumors started with RT-PCR for EWS and SSX translocations and since that time the spectrum of molecular investigations of bone and soft tissue tumors is constantly increasing (> Fig. 1). In 2013 FISH diagnostics for bone lesions was introduced. The molecular diagnostics is performed on all type of material (liquid, fresh, fresh frozen and FFPE as well as cytological preparations - smears and cytoblocks).

Over years the team has produced or significantly taken part in scientific work concerning the field of orthopaedics, producing a substantial number of publications, both clinical and experimental ( 1 - 29), as well as several PhD theses (four) mainly with clinical colleagues.
Authors

Batelja - Vuletic L

Institute of Pathology

Medical Faculty, University of Zagreb

Salata 10

CRO-10000 Zagreb

Seiwerth S

Institute of Pathology

Medical Faculty, University of Zagreb

Salata 10

CRO-10000 Zagreb

\section{Corresponding author}

Prof. Dr. med. Sven Seiwerth

Institute of Pathology

Medical Faculty, University of Zagreb

Salata 10

CRO-10000 Zagreb

\section{List of publications}

[1] Perovic D, Kolenc D, Bilic V et al. Stable gastric pentadecapeptide BPC 157 can improve the healing course of spinal cord injury and lead to functional recovery in rats. J Orthop Surg Res 2019; 14: 199. doi:10.1186/ s13018-019-1242-6.

[2] Seiwerth S, Rucman R, Turkovic B et al. BPC 157 and Standard Angiogenic Growth Factors. Gastrointestinal Tract Healing, Lessons from Tendon, Ligament, Muscle and Bone Healing. Curr Pharm Des 2018; 24: 1972-1989

[3] Bergovec M, Smerdelj M, Bacan F et al. Intraarticular synovial sarcoma of the knee rising from a lateral meniscus - a case report. Orthop Traumatol Surg Res 2018; 104: $227-230$ 


\section{- Rt-PCR (SINCE 2003) - 1218}

RT-PCR SARCOMAS

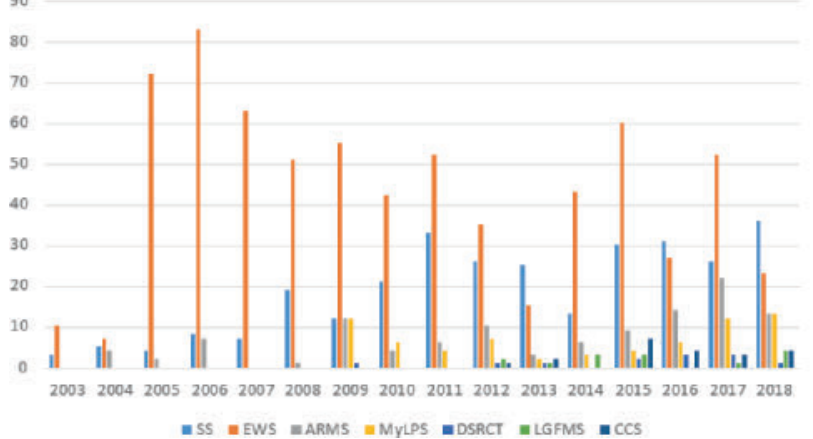

- Fig. 1 Molecular Pathology in sarcomas

RT-PCR. SS = Synovial Sarcoma, EWS = Ewing Sarcoma, ARMS =

Alveolar Rhabdomyosarcoma, MyLPS = Myxoid Liposarcoma, DSRCT

= Desmoplastic Small Round Cell Tumor, LGFMS = Low Grade Fibromy-

xoid Sarcoma, CCS = Clear Cell Sarcoma

\section{- FISH (SINCE 2013) - 200}

FISH SARCOMAS

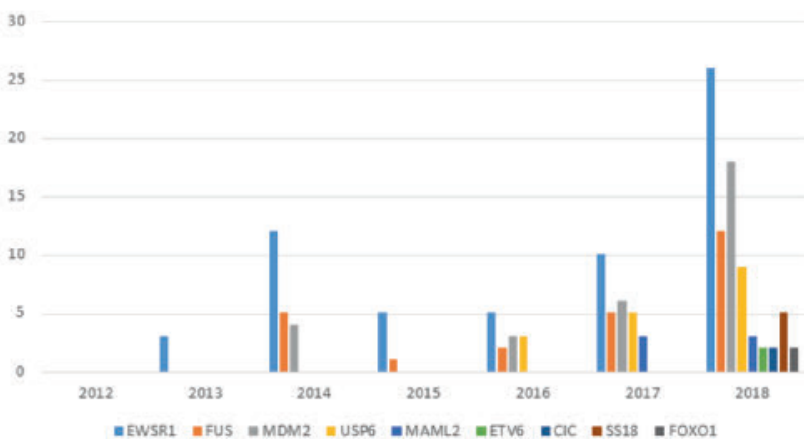

- Fig 2 Fluorescence in situ Hybridization (FISH). List of investigated genes: EWSR1, FUS, MDM2, USP6, MAML2, ETV6, CIC, SS18, FOXO1.
[4] Gabric D, Seiwerth S, Baraba A et al. Mandibular Osteonecrosis due to the Pulpal-Periodontal Syndrome: a Case Report and Review of the Literature. Acta Stomatol Croat 2017; 51: 65-71

[5] Barbaric K, Prutki M, Starcevic D et al. Rare localisation of osteoid osteoma. Acta Med Croatica 2016; 70: 191-195

[6] Vukic Dugac A, Hecimovic A, Jankoviç Makek $M$ et al. Pathological fracture and osteolysis of the rib with pleural effusion - is this malignant? Neth J Med 2016; 74: 369

[7] Bergovec M, Kubat O, Smerdelj M et al. Epidemiology of musculoskeletal tumors in a national referral orthopedic department. A study of 3482 cases. Cancer Epidemiol 2015; 39 (3): 298-302

[8] Antabak A, Papes D, Haluzan D et al. Reducing damage to the periosteal capillary network caused by internal fixation plating: An experimental study. Injury 2015; 46 (Suppl 6): S18-20. doi: 10.1016

[9] Antabak A, Dapic T, Seiwerth S et al. Subungual exostosis. Lijec Vjesn 2015; 137: 233-235

[10] Bergovec M, Petkovic M, Smerdelj M et al. Giant cell tumor of bone: results and treatment complications. Acta Med Croatica 2014; 68: 405-410

[11] Pecina M, Bojanic I, Ivkovic A et al. Patellar tendinopathy: histopathological examination and follow-up of surgical treatment. Acta Chir Orthop Traumatol Cech 2010; 77: 277-283

[12] Bojanic I, Vuletic LB, Troha I et al. Synovial chondromatosis Lijec Vjesn 2010; 132: 102-110

[13] Cerovecki T, Bojanic I, Brcic L et al. Pentadecapeptide BPC 157 (PL 14736) improves ligament healing in

the rat. J Orthop Res 2010; 28: 1155-1161. doi: 10.1002/jor.21107

[14] Pevec D, Novinscak T, Brcic L et al. Impact of pentadecapeptide BPC 157 on muscle healing impaired by systemic corticosteroid application. Med Sci Monit 2010; 16: 81-88

[15] Brcic L, Brcic I, Staresinic M et al. Modulatory effect of gastric pentadecapeptide BPC 157 on angiogenesis in muscle and tendon healing. J Physiol Pharmacol. 2009; 60 (Suppl 7): 191-196

[16] Pakos EE, Nearchou AD, Grimer RJ et al. Prognostic factors and outcomes for osteosarcoma: an international collaboration. Eur J Cancer. 2009; 45: 2367-2375

[17] Bekic M, Davila S, Hrskanovic M et al. Application of a novel bone osteotomy plate leads to reduction in -induced bone tissue necrosis in sheep. Coll Antropol 2008; 32: 1229-1237

[18] Krivic A, Majerovic M, Jelic I et al. Modulation of early functional recovery of Achilles tendon to bone unit after transection by BPC 157 and methylprednisolone. Inflamm Res 2008; 57: 205-210. doi: 10.1007/s00011007-7056-8

[19] Brcic L, Jakovcevic A, Vuletic LB et al. Pleomorphic liposarcoma of the foot: a case report. Diagn Pathol. 2008; 3: 15. doi: 10.1186/1746-1596-3-15

[20] Brcic L, Vuletic LB, Stepan J et al. Mast-cell sarcoma of the tibia. I Clin Pathol 2007; 60: 424-425

[21] Staresinic M, Petrovic I, Novinscak T et al. Effective therapy of transected quadriceps muscle in rat: Gastric pentadecapeptide BPC 157. J Orthop Res 2006; 24: 1109-1117
[22] Mikulic D, Ilic I, Cepulic M et al. Angiogenesis and Ewing sarcoma - relationship to pulmonary metastasis and survival. J Pediatr Surg 2006; 41: 524-529

[23] Krivic A, Anic T, Seiwerth S et al. Achilles detachment in rat and stable gastric pentadecapeptide BPC 157: Promoted tendon-to-bone healing and opposed corticosteroid aggravation. J Orthop Res 2006; 24: 982-989

[24] Mikulic D, Ilic I, Cepulic M et al. Tumor angiogenesis and outcome in osteosarcoma. Pediatr Hematol Oncol 2004; 21: 611-619

[25] Ilic I, Manojlovic S, Cepulic M et al. Osteosarcoma and Ewing's sarcoma in children and adolescents: retrospective clinicopathological study. Croat Med J 2004; 45: 740-745

[26] Seiwerth S, Brüschke C, Wiens J et al. Intrasternal respiratory epithelium-lined foregut cyst. J Thorac Cardiovasc Surg 2004; 127: $289-291$

[27] Staresinic M, Sebecic B, Patrlj L et al. Gastric pentadecapeptide BPC 157 accelerates healing of transected rat Achilles tendon and in vitro stimulates tendocytes growth. J Orthop Res 2003; 21: 976-983

[28] Kruslin B, Visnjic A, Cizmic A et al. DNA ploidy analysis and cell proliferation in congenital sacrococcygeal teratomas. Cancer 2000; 89 (4): 932-937

[29] Sebecic B, Nikolic V, Sikiric P et al. Osteogenic effect of a gastric pentadecapeptide, BPC-157, on the healing of segmental bone defect in rabbits: a comparison with bone marrow and autologous cortical bone implantation. Bone 1999; 24: 195-202 